\title{
Análise Combinatória: do método aleatório à combinatória sistemática
}

\author{
Mariana Lima Duro' \\ Fernando Becker'
}

'Universidade Federal do Rio Grande do Sul (UFRGS), Porto Alegre/RS - Brasil

RESUMO - Análise Combinatória: do método aleatório à combinatória sistemática. Nesta pesquisa busca-se compreender a psicogênese do pensamento combinatório na perspectiva da Epistemologia Genética de Jean Piaget. Analisa-se os mecanismos utilizados por estudantes do ensino médio na resolução de situações experimentais de análise combinatória, no intuito de compreender como esta noção é construída por eles. O pensamento dos sujeitos é analisado ressaltando suas semelhanças, enquanto estruturas de raciocínio, na construção de possibilidades. Acredita-se que alguns métodos escolares possam prejudicar a construção do raciocínio formal, justificando as dificuldades dos jovens em compreender mecanismos combinatórios.

Palavras-chave: Combinatória. Epistemologia Genética. Aprendizagem. Matemática.

ABSTRACT - Combinatorial Analysis: from random method to systematic combinatorics. This research seeks to understand the psychogenesis of the combinatorial thought from the perspective of the genetic epistemology of Jean Piaget. It analyzes the mechanisms used by high school students in solving combinatorial analysis of experimental situations in order to understand how this notion is built by them. The thought of the subjects is analyzed emphasizing their similarities, as reasoning structures, when building possibilities. We believe that some school methods can hinder the construction of the formal reasoning, explaining the difficulties of young people in understanding combinatorial mechanisms.

Keywords: Combinatorics. Genetic Epistemology. Learning. Mathematics.

Educação \& Realidade, Porto Alegre, v. 40, n. 3, p. 859-882, jul./set. 2015. 859 http://dx.doi.org/10.1590/2175-623641714 


\section{Introdução: compreendendo o problema}

Esta pesquisa pretende levantar hipóteses acerca do pensamento lógico, do ponto de vista da Epistemologia Genética, do aluno do Ensino Médio. A aquisição de estruturas formais de pensamento possibilita a construção do raciocínio lógico-matemático do sujeito, enquanto superação da intuição perceptiva do período pré-operatório, e da reversibilidade limitada das ações operatório-concretas.

Procura-se investigar as estratégias utilizadas pelos estudantes durante a realização de experimentos, levando em conta a estruturação do seu raciocínio e os esquemas previamente construídos que possibilitam ou limitam a construção da combinatória. Dessa forma, pretende-se contribuir com as pesquisas na área de ensino de matemática, à medida que o professor-leitor poderá refletir sobre os diferentes níveis de pensamento dos seus alunos, e não mais partir do pressuposto de que todos já possuam raciocínio formal estruturado para a aprendizagem da combinatória.

[...] a Matemática não é um esporte para espectadores: não pode ser apreciada e aprendida sem participação ativa, de modo que o princípio da aprendizagem ativa é particularmente importante para nós, matemáticos professores, tanto mais se tivermos como objetivo principal, ou como um dos objetivos mais importantes, ensinar crianças a pensar (Polya, 1985, p. 13).

Concebendo o aluno como sujeito ativo de sua própria aprendizagem e com subsídio da Epistemologia Genética de Jean Piaget, busca-se compreender como alunos do ensino médio aprendem combinatória. Desta maneira, o leitor é convidado a refletir acerca do ensino desse conteúdo, de modo a pensar em estratégias didáticas que favoreçam a aquisição de estruturas capazes de assimilá-lo.

Em geral, todos os seres humanos são capazes de chegar ao nível das estruturas formais, tendo em vista que a relação estabelecida pelo sujeito entre os meios endógeno e exógeno possibilita sua construção. Sendo assim, como se dá o processo de construção da combinatória? Como o sujeito passa a distanciar-se do real e parte para o plano das possibilidades? Como se dá a ação no plano virtual? Ao pensar sobre essas questões, tomamos consciência do quanto a Epistemologia Genética pode contribuir para compreendermos o desenvolvimento das estruturas cognitivas. Polya (1985) afirma que:

Se quisermos desenvolver a inteligência do aluno, devemos ficar atentos para que as coisas primeiras apareçam em primeiro lugar. Certas atividades são mais fáceis e naturais que outras: adivinhar é mais fácil que demonstrar, resolver problemas concretos é mais natural do que construir estruturas conceituais (Polya, 1985, p. 13).

860 Educação \& Realidade, Porto Alegre, v. 40, n. 3, p. 859-882, jul./set. 2015. 
Em geral, o concreto vem antes do abstrato, a ação e a percepção, antes das palavras e dos conceitos, os conceitos, antes dos símbolos etc. Levando-se em conta que uma informação somente pode ser compreendida se o sujeito possuir estruturas internas que lhe possibilitem assimilá-la, torna-se impossível ensinar conceitos matemáticos complexos a crianças que ainda não desenvolveram estruturas para isso. No entanto, há um consenso entre os professores de que "[...] o conhecimento não passa de uma acumulação de aprendizagens, compreendidas como cópias; daí, a onipresença da estimulação como explicação das aprendizagens, independentes da atividade do sujeito" (Becker, 1998, p. 53).

Para pensar no plano hipotético e entrar no mundo das possibilidades, é necessário que o sujeito coordene suas ações, de modo a transpor a um plano mental superior o seu pensamento atual. Nesse novo plano, novas reorganizações serão estabelecidas. Nesse sentido, Piaget (1995) afirma que as estruturas de pensamento são estruturadas e estruturantes ao mesmo tempo.

\section{Coleta de Dados: a busca por respostas}

A coleta de dados para esta pesquisa deu-se por meio de provas experimentais concretas, que favorecessem ao sujeito a construção de cálculos combinatórios. A aplicação desses experimentos teve inspiração no método clínico piagetiano, que permite intervenções do experimentador questionando o sujeito em busca da compreensão da gênese do seu pensamento a respeito da noção ou conceito em pauta. As questões formuladas estão de acordo com as respostas dadas pelo sujeito ou por suas atitudes, nas diferentes situações a que estiver exposto, devendo ser analisados todos os aspectos considerados relevantes para a pesquisa.

O método clínico prevê coleta e análise de dados feitos de maneira que possibilite compreender, através da fala e do comportamento, o pensamento dos sujeitos. Compreender o seu pensamento significa compreender "[...] como ele organiza seu pensamento, como ele percebe, age e sente" (Delval, 2002, p. 67). O objetivo de cada pergunta estava voltado a descobrir como o sujeito pensa. A liberdade limitada - no sentido de não fugir dos objetivos - que o método possibilita, permite à entrevistadora dar conta da grande diversidade de possibilidade de respostas e de intervenções que surgiram durante as experiências. A metodologia escolhida para a aplicação e análise dos experimentos exige um grande domínio teórico da experimentadora e uma objetividade segura quanto a sua investigação, à medida que suas hipóteses, acerca do pensamento do sujeito, estiverem em constantes reformulações.

Entende-se que investigar com experimentos práticos ativa a operatoriedade do sujeito, favorecendo a sistematização do pensamento, além de possibilitar a compreensão, com maior clareza, dos mecanismos que levam o sujeito à determinada solução. Além disso, possibilita 
a reflexão do sujeito sobre sua própria ação e, mais ainda, sobre as coordenações de suas ações. A manipulação dos experimentos permite aos alunos testarem suas hipóteses, refletirem sobre suas ideias e modificá-las, caso entrem em contradições. Além disso, a ação concreta pode auxiliá-los na criação de novas conjecturas que servirão de patamares para novos saberes. A contradição é outra técnica utilizada, para que o próprio sujeito aceite ou refute a nova informação. É papel da experimentadora, acompanhar o desenvolvimento do pensamento do sujeito e ter em mente o objetivo de sua busca.

Dolle e Bellano (2002) comentam sobre o método clínico como uma evolução da observação pura, pela qual Piaget iniciou suas pesquisas que procurou, de forma sistematizada, proporcionar conversas livres. Mas não são, unicamente, as respostas dadas pelas crianças às perguntas propostas, mesmo que de forma espontânea, que bastam para Piaget. É importante interferir nessas respostas de modo oportuno, expondo-as a novas perguntas, tentando sempre clarificar as estruturas de seus pensamentos. As perguntas devem ser feitas de maneira diferente a cada vez, de modo a não induzir determinada resposta, sequer sugeri-la.

O método clínico utiliza o critério da saturação para determinar a quantidade de sujeitos. Dessa maneira, foram entrevistados 18 sujeitos, sendo oito alunos de EJA e 10 alunos do ensino médio regular. A partir do momento em que nada de novo, em termos de estrutura, apareceu nas explicações dadas pelos sujeitos, foi encerrada a coleta de dados. Os sujeitos da pesquisa foram selecionados entre os alunos regularmente matriculados no ensino médio regular ou EJA, de uma escola da rede pública; não se fez restrição à idade dos sujeitos participantes. Independentemente de esses sujeitos já terem tido contato com o conteúdo de análise combinatória em qualquer tempo e espaço, o nosso objetivo era compreender como esse raciocínio se desenvolve no sujeito. Ter estudado análise combinatória não pressupõe ter aprendido análise combinatória. As idades dos alunos pesquisados variavam entre 14 e 47 anos. Todos os sujeitos encontravam-se em processo de escolarização formal, estando em uma das três séries do ensino médio, seja ele regular ou EJA. O convite para participar da coleta de dados desta pesquisa levou em consideração a disponibilidade dos sujeitos. 
Duro; Becker

Quadro 1 - Sujeitos da pesquisa por idade, série e nível de ensino

\begin{tabular}{|c|c|c|c|}
\hline Sujeito & Idade & Ano & Modalidade \\
\hline A & 14 & $1^{o}$ & Regular \\
\hline B & 14 & $1^{o}$ & Regular \\
\hline $\mathrm{C}$ & 15 & $1^{o}$ & Regular \\
\hline $\mathrm{D}$ & 15 & $1^{o}$ & Regular \\
\hline $\mathrm{E}$ & 16 & $2^{o}$ & Regular \\
\hline $\mathrm{F}$ & 16 & $2^{o}$ & Regular \\
\hline G & 16 & $2^{o}$ & Regular \\
\hline $\mathrm{H}$ & 17 & $3^{\circ}$ & Regular \\
\hline I & 17 & $3^{\circ}$ & Regular \\
\hline $\mathrm{J}$ & 17 & $3^{\circ}$ & Regular \\
\hline K & 18 & $1^{o}$ & EJA \\
\hline $\mathrm{L}$ & 22 & $1^{o}$ & EJA \\
\hline M & 27 & $2^{o}$ & EJA \\
\hline $\mathrm{N}$ & 32 & $3^{\circ}$ & EJA \\
\hline $\mathrm{O}$ & 36 & $3^{\circ}$ & EJA \\
\hline $\mathrm{P}$ & 42 & $2^{o}$ & EJA \\
\hline Q & 44 & $1^{o}$ & EJA \\
\hline $\mathrm{R}$ & 47 & $2^{o}$ & EJA \\
\hline
\end{tabular}

Fonte: elaboração dos autores.

Para a coleta de dados foram elaborados três diferentes experimentos, aplicados individualmente em alunos estudantes do ensino médio regular e EJA. As entrevistas foram filmadas a fim de obter maior fidelidade em suas transcrições. Com intervenções constantes, sujeito e entrevistadora mantiveram uma conversa livre, porém com o devido cuidado, da parte desta, de não sugerir respostas, corretas ou não. Durante a aplicação das provas combinatórias, foram feitos questionamentos e contra-argumentações que exigiam dos entrevistados organizar suas ações em nível mental, recriando-as e modificando-as quando julgavam necessário. A contra-argumentação consiste em argumentar determinada resposta de modo contrário à resposta dada pelo sujeito.

Educação \& Realidade, Porto Alegre, v. 40, n. 3, p. 859-882, jul./set. 2015. 


\section{Instrumentos de Coleta de Dados}

A criação das provas se deu a partir de três experimentos criados pela autora. A ideia de partir de um problema de menor complexidade para um de maior complexidade possibilitaria que os sujeitos esquematizassem seu pensamento e construíssem sua própria formalização acerca do problema, saindo do plano concreto e avançando para o mundo das hipóteses. As atividades experimentais privilegiam as ações do sujeito, não só as ações práticas, mas também as ações mentais que vão acontecendo à medida que novos desafios se propõem. Mesmo com as dificuldades e limitações que a materialidade oferece, os questionamentos e proposições podem seguir indefinidamente, em pensamento.

\section{Experimento 1:}

Material utilizado: O material utilizado para a confecção desse experimento consiste em quatro representações de casas de material plástico, cada uma de uma cor: Amarela (A), Azul (Z), Rosa (R) e Roxa (X). As estradas que delineiam os caminhos que ligam uma casa a outra são móveis (não-fixas) e foram confeccionados de E.V.A., dando a possibilidade de o sujeito segui-los com o auxílio de um carrinho de brinquedo.

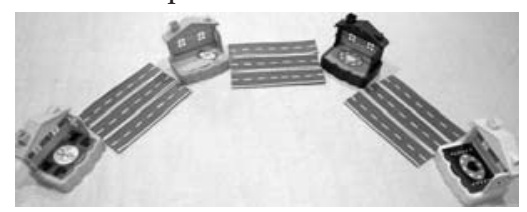

Procedimento: Primeiramente distribuem-se três casas sobre a mesa (A, Z e R), em seguida, coloca-se uma estrada entre A e Z e outra entre Z e R. Sucessivamente vão sendo colocadas mais estradas entre elas. O objetivo desta primeira etapa é que o sujeito compreenda a diferença entre estradas e caminhos, visto que ligando mais de uma estrada podemos obter um único caminho.

Nas próximas etapas são dispostas mais casas e estradas sobre a mesa, perguntando-se, por exemplo: Quantas estradas existem? Quantos caminhos existem que levem de $\mathrm{Z}$ a X, passando por R? Qual a maior quantidade de caminhos que podemos ter? E se tivéssemos mais estradas? Existe alguma relação entre as respostas dadas nas situações? O sujeito deverá responder, justificando sua resposta e contra-argumentando quando necessário.
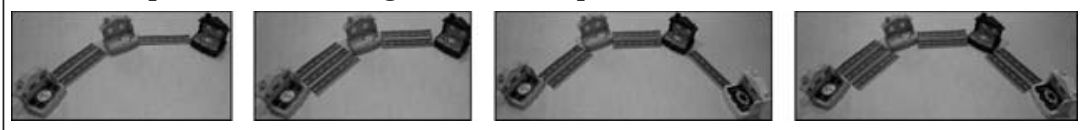

No primeiro experimento ${ }^{1}$, chega-se a um momento em que fica inviável representar a grande quantidade de caminhos de modo empírico. Para ter certeza da quantidade de caminhos que materialmente é capaz de construir, o sujeito precisa, em nível mais elementar, sistematizar seu pensamento por meio de uma representação em forma de árvore ou, em nível mais elevado, estruturar seu pensamento a fim de construir um raciocínio multiplicativo e, assim, generalizá-lo para 
quantos caminhos seu pensamento é capaz de criar. É essa possibilidade de continuar o pensamento sem o material concreto que caracterizaria um pensamento combinatório formalmente construído. Para realizar este experimento, no entanto, não se exige que o sujeito já tenha estudado o conteúdo matemático de análise combinatória, requer apenas que o sujeito elabore um raciocínio baseado no PFC.

\section{Experimento 2:}

Material utilizado: O material utilizado consiste de uma mesa e quatro cadeiras confeccionadas em madeira e cinco bonecos que deverão ocupá-las.
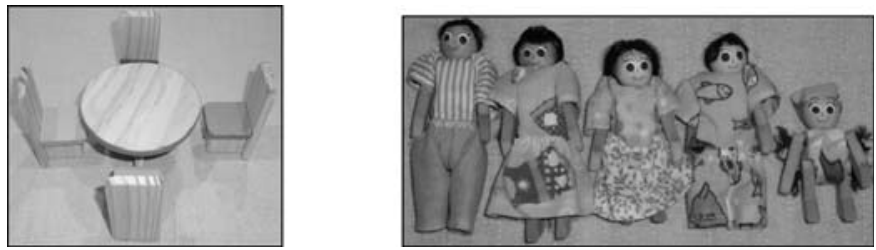

Procedimento: O experimento 2 consiste nas Provas 2 e 3 , que buscam determinar a quantidade de maneiras de um grupo de quatro (permutação) ou cinco (arranjo) pessoas sentarem-se a uma mesa de quatro lugares. Para efeito de maior esclarecimento sobre o experimento, discutiremos sobre o primeiro caso (distribuir quatro pessoas em quatro lugares), levando em conta que o raciocínio referente a cinco pessoas é feito de modo análogo. $\mathrm{O}$ experimento permite ainda que se trabalhe com uma quantidade menor de elementos, a fim de adequar ao nível de pensamento do sujeito.

Distribuem-se sobre a mesa quatro cadeiras e quatro bonecos diferentes. Em seguida, pede-se que o sujeito distribua um boneco para cada cadeira. A partir daí pergunta-se: quantas são as possibilidades de configuração diferentes para a família sentar-se à mesa? Existe mais alguma possibilidade que você não contou? Como você tem certeza de que contemplou todas as possibilidades? É possível saber quantas são as diferentes permutações de pessoas? E se houvesse mais cadeiras? E mais pessoas? E se não houvesse limitação material? Caso o sujeito não compreenda a atividade, pode iniciar com duas ou três pessoas e cadeiras.
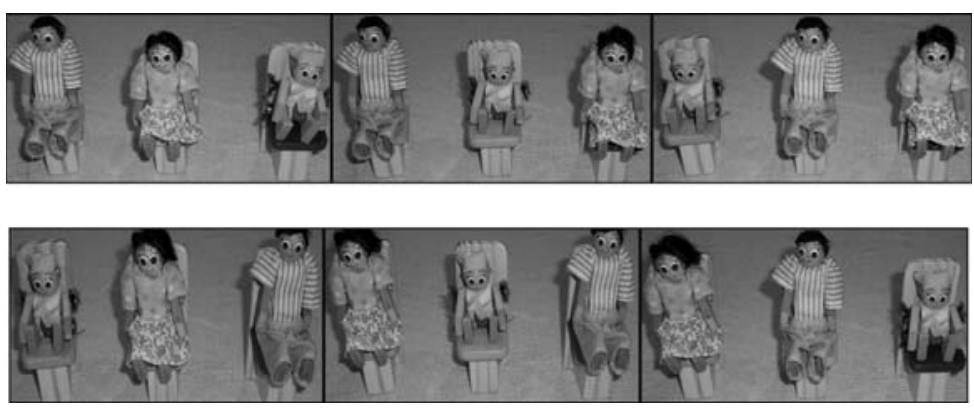

Este experimento está relacionado aos conteúdos de arranjo e permutação, porém não é necessário que o sujeito conheça esses conceitos para desenvolver eficientes mecanismos de cálculo. 


Experimento 3:
Material utilizado: Um pentágono, um hexágono, um heptágono e um octógo-
no regulares, confeccionados em madeira, contendo pregos em seus vértices
e atilhos.
Procedimento: Esse material permite que o sujeito, com auxílio de um atilho,
consiga formar triângulos, cujos vértices coincidam com os vértices do hexá-
gono. O objetivo é descobrir a quantidade de triângulos diferentes (com vér-
tices distintos) capazes de serem compostos, unindo os vértices de um dos
polígonos escolhidos.
- É possível formar mais algum triângulo?
- Como você sabe?
- Nesta conta, há triângulos repetidos?
- Quantos?
- Qual seria a estratégia para contar apenas os triângulos não repetidos?
-Qual a semelhança deste experimento com os anteriores?

O terceiro experimento desenvolvido prevê um raciocínio que exclua as possibilidades que geram resultados equivalentes, conforme já explicado no subcapítulo referente à combinação simples. Esta prova pode ter continuidade com os polígonos com maior quantidade de lados e, assim, mais vértices disponíveis para a combinação.

É através da estratégia de contagem e da explicação que é possível verificar como o sujeito concebe a enumerabilidade da quantidade de triângulos distintos. Embora os experimentos estejam restritos a situações de quantidades finitas, é possível verificar até que ponto o sujeito consegue trabalhar no plano das ideias, generalizando o seu pensar a fim de aplicar a forma estabelecida e um novo conteúdo apresentado. A finalidade de questionar sobre as possibilidades para além das que o material permite fazer é observar como os sujeitos fazem a distinção entre o possível real e virtual. Alguns não conseguem fazer essa relação e só conseguem responder à pergunta, utilizando-se do concreto; outros passam a relacionar real e virtual a partir do experimento.

\section{Apresentação e Análise dos Dados}

Piaget utiliza modelos lógicos para representar a estrutura do pensamento. Os modelos lógicos por ele estudados tendem a representar a essência e não cópias do pensamento do sujeito. Dessa maneira, foi possível configurar uma estruturação operatória fundada sobre a lógica 
das proposições e sobre um pensamento formal. Nesta pesquisa, pode-se observar três níveis de pensamento, cada um subdividido em dois subníveis. Deixa-se claro que os níveis e subníveis estão relacionados às noções avaliadas (e não outras), podendo o sujeito estar em diferentes níveis de pensamento tratando-se de noções diferentes.

Ou seja, nesta pesquisa, não foi realizada uma avaliação para verificar o nível de pensamento do sujeito em toda sua complexidade, mas que os níveis, abaixo descritos, referem-se à noção estudada através dos experimentos. Embora, muito provavelmente, os níveis encontrados em relação às noções de combinatória repitam-se em outras áreas, estas não foram avaliadas de forma sistemática e, por isso, não podemos afirmar que aconteçam. Ou seja, não interessa, aqui, analisar os sujeitos, mas o que interessa é analisar as respostas do sujeito quanto à noção de análise combinatória.

Abaixo, os trechos destacados em itálico ao longo do texto representam partes das falas dos sujeitos entrevistados.

\section{Nível I}

\section{Ausência de Sistematização Multiplicativa}

Os sujeitos do Nível I contextualizam suas respostas, embora sem indícios de raciocínio combinatório em seu esforço para encontrar a solução do problema. Neste nível, os sujeitos baseiam-se em abstrações muitas vezes de maneira aleatória. Os elementos são associados dois a dois, não havendo indícios de sistematizações multiplicativas. As explicações são pré-causais, vinculadas ao mundo real.

Os sujeitos descrevem o que podem ver. Para os casos mais simples, as multiplicações se dão, de certa forma, por pequenas organizações estruturadas. No entanto, cada vez menos sistemáticas, quanto maior o número de variáveis a ser dissociadas. Os sujeitos se satisfazem com explicações diferentes e, até, contraditórias entre si. Ficam indiferentes frente à contradição, pois, mesmo testando suas hipóteses em diversas tentativas, os sujeitos não coordenam estes resultados. Não procuram tornar dedutível o real. Acreditam que o acaso é que determina as possibilidades, e nem imaginam que situações semelhantes geram resultados semelhantes.

Os sujeitos deste nível de pensamento não buscam, ainda, uma explicação única e não contraditória para os problemas de combinatória. Estando em um nível de pensamento pré-operatório, tratando-se das noções avaliadas pelo experimento, esses sujeitos podem apresentar êxito ou fracasso na ação prática, porém, desconsideram os mecanismos que os levaram para tal solução. Buscam o resultado, não mostrando consciência do processo. Não buscam a interiorização de suas ações (Inhelder; Piaget, 1976).

Educação \& Realidade, Porto Alegre, v. 40, n. 3, p. 859-882, jul./set. 2015. 


\section{Subnivel IA: ausência de sistematização}

Os sujeitos do subnível IA fazem associações aleatórias, relacionando combinações de modo não sistemático. O sujeito A só admite caminhos retos, deixando de lado algumas combinações: Eu posso pegar a primeira estrada (A1) e depois a segunda (B1), ou eu posso pegar a segunda estrada daqui (A2) e depois a outra do outro lado (B2). Não consegue sistematizar seu pensamento a fim de afirmar o conjunto de possibilidades e verificá-las, não encontrando as possibilidades A1B2 e A2B1, por exemplo. Se tem três estradas daqui pra cá (casa Azul à casa Amarela) $e$ mais três estradas daqui pra cá (casa Amarela à Roxa), tem quatro ou seis caminhos no total, eu acho.

$\mathrm{K}$ desviou do problema, inventando novos problemas relacionados ao real. Não sei bem quantos caminhos, pois depende também se as estradas estão boas. O mesmo tipo de pensamento surgiu no experimento seguinte: Para sentarem-se à mesa eles precisam ter afinidade um com o outro. Não é bem assim, para sentá-los em qualquer lugar.

\section{Subnível IB: sistematização aditiva}

Os sujeitos deste nível utilizam a adição como técnica de sistematização. À medida que são acrescentados elementos, o sujeito soma essa quantidade às combinações já efetuadas. As soluções se limitam a uma adição sem compreensão. Neste nível, os sujeitos mantêm um raciocínio subordinado ao conteúdo concreto, uma vez que as combinações possíveis são as que pode ver, mesmo que não fisicamente, mas enquanto pensamento. Esse pensamento está, pois, dominado pela percepção. Os sujeitos não se afetam com a contradição ao perceberem a existência de outro caminho, não contabilizados anteriormente como possibilidade.

B esquematiza o pensamento do ponto de vista aditivo: Acho que aumentando duas estradas, aumentam-se dois caminhos, oito então. B ainda consegue organizar seu pensamento de modo a construir possibilidades, quando se trata de até duas variáveis, mas quando essas quantidades aumentam, não consegue pensar da mesma forma, tendo certeza de que não existe nenhuma outra possibilidade de caminho. Não, são só esses [caminhos] mesmo, eu contei. No experimento 2, contendo três cadeiras e três pessoas, afirma que cada pessoa pode sentar em cada cadeira uma vez, o que resulta em três, mais três, mais três. Nove possibilidades. No experimento 3, faz alguns triângulos aleatórios e não consegue afirmar se tem certeza de que são todas as possibilidades. $\mathrm{N}$ prende-se ao real, organizando seu pensamento de acordo com situações reais de direção. Não posso mudar a faixa, pois não há rotatória.

Mesmo que se tente mostrar para o sujeito do nível I mais uma possibilidade, isso não basta para que modifique sua estrutura lógica. A experiência física pode ser importante, mas nunca suficiente para modificar uma estrutura de pensamento, ou seja, ela não pode ser obtida

868 Educação \& Realidade, Porto Alegre, v. 40, n. 3, p. 859-882, jul./set. 2015. 
por reforço externo, pois o sujeito deve estar pronto também internamente para responder ao estímulo externo, por ocasião da experiência. Dessa forma, os experimentos, por si só, não são capazes de alterar ou corrigir o pensamento do sujeito. Para conciliar suas explicações em uma única totalidade que englobe todas as possibilidades, é necessário que suas ações sejam interiorizadas e que essas operações se tornem conscientes.

\section{Nível II}

\section{Início da Sistematização Multiplicativa}

O sujeito deste nível é capaz de ordenar e seriar adequadamente as variáveis, mas não consegue dissociá-las, fazendo-as variar ao mesmo tempo; isso torna impossível a verificação correta da solução. Os sujeitos do nível II, diferentemente dos do nível I, não ficam limitados apenas à ação prática e buscam interiorizar os mecanismos utilizados nesta ação na medida em que buscam apropriar-se das próprias ações. Mas, "[...] a ausência de um sistema combinatório faz com o que o sujeito desse estádio caminhe passo a passo, realizando ligações parciais, sem chegar a relacionar cada uma dessas reuniões com as demais" (Parra, 1983, p. 23). Ou seja, da mesma forma que o sujeito operatório concreto não chega a retirar dessas ações uma correspondência geral que possa levá-lo a uma organização combinatória formal.

É no Nível II que ocorrem as primeiras aproximações da solução combinatória mais geral, embora ainda não sejam utilizados procedimentos de enumeração sistemática. Os sujeitos possuem um pensamento parcial, ou seja, conseguem esquematizar seu pensamento de modo a encontrar todas as possibilidades, mas a forma encontrada ainda não pode ser aplicada a diferentes conteúdos.

\section{Subnível IIA: correspondência biunívoca entre variáveis}

O sujeito em transição para o nível IIA apresenta seu estado de desequilíbrio no momento em que não vê como suficiente o cálculo aleatório de combinações, estando no início das operações concretas. Para superar tais contradições, e com real esforço para isso, é que esses sujeitos passam a buscar a lei.

[...] a leitura da experiência bruta se torna possível graças a classificações, seriações e correspondências coerentes e diferenciadas, mas isso de forma alguma é suficiente para assegurar a dissociação de fatores, isto é, para assegurar a organização de uma experiência verdadeira (Inhelder; Piaget, 1976, p. 36).

O sujeito faz uma leitura sistemática da experiência física, sem objetivar a verificação de hipóteses sobre dissociação de fatores. A sua 
Análise Combinatória

estrutura mental concreta é suficiente para ler os fatos, mas não para organizá-los em termos de dissociação. O sujeito busca a verificação, mas não possui a estrutura completa de operações interproposicionais. Ele passa a sistematizar seu pensamento, embora essa sistematização seja precária, no sentido de não contemplar todas as combinações. Apenas um fator é escolhido para combinar com os demais, enquanto ele mesmo não varia, combinando-se com os demais. Quando solicitado a fazer novas combinações com as combinações já efetuadas, regride ao caráter empírico e às combinações casuais próprias do nível I.

$\mathrm{L}$ afirma ter feito todas as combinações no primeiro experimento, mas não consegue mostrá-las, encontrando um número diferente de possibilidades a cada tentativa. Acho que fiz todas. Daria para fazer mais alguma? Não sei. Recomeçam as tentativas, uma vez que as combinações já efetuadas não podem ser coordenadas com as novas. Se não está dando certo o número que tu encontras com o número que achas que deveria ser, o que poderias fazer diferente? L continua não fazendo combinações de combinações. Poderíamos continuar a aumentar a quantidade de caminhos? Sim. Quantos caminhos mais poderias fazer? Podes fazer mais, talvez mais umas dez, vinte vezes, até mais. Esta resposta mostra que, em seu pensamento, a infinidade não existe. Embora seja possível criar muitos caminhos, ainda não é possível compreender a infinidade, que só existe no pensamento.

M, no entanto, com quatro casas não consegue utilizar o mesmo pensamento sistemático, responde com êxito, utilizando-se do Princípio Multiplicativo, mas não consegue apontar a quantidade total de caminhos. A lógica existe... multiplicar. A regra é continuar multiplicando. Mostrar é bem difícil. Não teria como mostrar os caminhos? Falta mostrar dois. Eu estava comparando, mas não consigo. Ou seja, M consegue combinar fatores de modo a relacioná-los dois a dois, mas ainda não consegue operar sobre operações, combinando as combinações já efetuadas e, muitas vezes, voltando a realizar combinações aleatórias.

O sujeito apresenta sua lógica relacional de correspondência biunívoca, um para um. Não consegue fazer combinações de segunda, terceira, quarta ordem, por falta de estrutura de pensamento. Algumas destas relações são até possíveis, mas não sistematizáveis. Essas combinações limitadas, que associam um termo a cada um dos outros, não permitem que, sozinho, o sujeito chegue às demais combinações. As operações apenas de primeira potência denotam capacidade de correspondência e seriação, mas não a capacidade combinatória que buscamos.

\section{Subnível IIB: dissociação dos fatores empíricos (combinações n a n)}

Os sujeitos deste nível apresentam considerável progresso se o assunto é superar as contradições, na busca de uma solução única; no entanto, nem sempre se veem livres das contradições, à medida que não 
possuem os esquemas operatórios necessários para isso. Isolam adequadamente as variáveis, porém, se utilizam de operações concretas (de seriação e correspondência), não procurando razão para a utilização dos mecanismos utilizados, não demonstrando possuir estruturas formais de implicação para a solução (Inhelder; Piaget, 1976).

Mesmo em posse de todos os elementos necessários para a criação da lei geral da combinatória, ainda lhes faltam as operações formais para a criação de uma hipótese explicativa. $\mathrm{O}$ ponto de partida para a descoberta desta lei é a necessidade de uma reciprocidade advinda das correspondências concretas. Uma estrada a mais implica mais caminhos, em proporção, tantos quantos forem as demais estradas, e reciprocamente. Trocar um familiar de lugar exige sua recíproca; outro também deverá ser trocado de lugar. As contradições mais simples são afastadas apenas pela ação concreta. As mais sutis pressupõem implicações, isto é, exigem uma lógica formal.

Esse sujeito encontra-se em um nível intermediário, entre o II e o III, visto que não chega a formular uma lei única, mas não aceita que ela não exista. Consegue testar suas hipóteses, mas não chega à solução geral. Neste nível, os sujeitos já chegam às combinações $n$ a $n$ através das sistematizações das multiplicações. O pensamento concreto e sem interesse na generalização se mantém igual ao nível IIA. A diferença está relacionada à abertura para as combinações de combinações, resultantes de combinações de segunda potência.

C mostra sinais de busca, de certa forma, de uma sistematização mais segura, mas sem a verificação de hipóteses. Eu posso deixar a mãe na primeira cadeira sempre, daí troco os outros, assim [mostra concretamente], depois faço a mesma coisa com o pai e o filho.

F diz: Sei que se eu for sempre por esta [estrada] poderei ir pelas outras, depois posso trocar. E se contasses ao contrário [da direita para a esquerda]? Posso contar daqui pra cá ou de lá pra cá que dá na mesma. Demonstrando a relação de reciprocidade. Preciso cuidar para não contar a mesma forma [disposição dos bonecos] duas vezes. E como tu podes ter certeza? Tenho que cuidar para não repetir. No último experimento consegue fazer novas combinações n a n, embora não encontrando todas as possibilidades. Primeiro vou fazer os triângulos com [vértice] A. Faz ABC, ABD, ABE, ignorando os triângulos ACD, ACE e ADE.

O método sistemático de obtenção das possibilidades permitiu a $\mathrm{H}$ pensar que pudesse haver uma regra, mas estava distante de suas possibilidades cognitivas. Esse caminho eu deixo parado, só combinando com os outros, pois este não faz nada. Como é que tu sabes que esse caminho não faz nada? Não sei, acho que deve haver uma regra, mas não é sempre a mesma. H é um exemplo de sujeito em transição em termos de nível de pensamento. Embora algumas vezes demonstre não fazer combinações sobre combinações, em outros momento parece ir ao encontro de uma lei geral que dê conta dos conflitos encontrados. 


\section{Nível III}

\section{Sistematizações Generalizadoras}

A principal propriedade do pensamento formal é a inserção da realidade como subconjunto de um conjunto maior de possibilidades. Em lugar de teorizar sobre dados empíricos (concretos), o pensamento formal permite que o sujeito teorize sobre possibilidades. Neste estádio, o sujeito é capaz de relacionar variáveis, utilizando-se da experimentação (ou não), apenas para testar, sobre um padrão sistemático, se suas hipóteses se mantêm verdadeiras (Parra, 1983). Esse raciocínio, que relaciona proposições e não conteúdos, caracteriza-se como hipotético-dedutivo.

Os sujeitos deste nível tentam compreender o resultado dentro de um universo de possibilidades. Concebem o real como uma organização de conjuntos possíveis. É muito longo o caminho que o pensamento percorre até a teorização, mediante raciocínios hipotético-dedutivos. Neste nível, os sujeitos conseguem chegar à lei geral da combinatória. Alguns, inclusive, tomam consciência de suas ações, durante a entrevista, por verificação ou rejeição de hipóteses.

Somente as hipóteses muito elementares são afastadas sem experimentação prévia, porém as demais são cada vez mais testadas em busca de uma solução única. A generalização é dada a partir das comparações efetuadas ainda no nível II. Nos experimentos 2 e 3, essas comparações ficam dificultadas em virtude de não ficarem afixadas a hipóteses já testadas. Além disso, nenhum dos experimentos dá certeza de êxito nas soluções.

Os sujeitos que serão analisados a seguir são mais capazes no momento de raciocinar combinatoriamente, talvez por estarem em um nível escolar no qual a combinatória já foi formalizada. Porém, se no momento do ensino, esses sujeitos ainda não operassem em nível formal, os conceitos envolvidos na análise combinatória não seriam compreendidos. Nesse caso, deveríamos constatar isso durante o interrogatório. Neste nível, há uma relação causal estabelecida por correspondência; por exemplo, quanto mais estradas mais caminhos, ou quanto mais cadeiras mais organizações possíveis, ou quanto mais vértices mais triângulos, em uma proporção multiplicativa.

Com o pensamento formal, a forma do sistema operatório combinatório é constituída e dissociada do conteúdo. Essa forma encontra-se em um último patamar de equilíbrio, podendo ser integrada a outros sistemas mais amplos, mas jamais modificada (Inhelder; Piaget, 1976).

\section{Subnível IIIA: combinação sistemática $n$ a $n$}

Esses sujeitos acreditam na existência de uma lei única e geral capaz de explicar o resultado obtido na ação empírica, mas ainda não 872 Educação \& Realidade, Porto Alegre, v. 40, n. 3, p. 859-882, jul./set. 2015. 
sentem a necessidade dessa formulação, obtendo êxito através de combinações n a n e de modo sistemático. Penso ser necessário manter o "e", pois uma coisa não é consequência da outra.

$$
\begin{aligned}
& \text { [...] as operações formais já estão suficientemente esboça- } \\
& \text { das, para que sejam possíveis algumas inferências, mas } \\
& \text { não ainda suficientemente organizadas para funcionar } \\
& \text { como esquema antecipatório (Inhelder; Piaget, 1976, p. 53). }
\end{aligned}
$$

D consegue encontrar todas as possibilidades de modo sistemático. Com três casas multiplica-se a quantidade de estradas entre elas. E com mais casas? Continuo a multiplicar. Como é que tu explicas isso? Para cada nova estrada aumenta outra possibilidade de caminho para cada estrada já existente. Sempre vai ser assim? Sim. Então qual é o maior número de caminhos que podemos ter? Se tivéssemos infinitas estradas, infinitos caminhos. Nos demais experimentos, consegue chegar ao êxito pela sistematização, mas não encontra lei única que os explique. Preciso escrever para lembrar as [combinações] que já fiz. Por quê? É preciso usar todas.

É esta necessidade de organização que diferencia o nível II do nível III. D necessita escrever, e essa necessidade deu-se de forma espontânea. Ter a certeza de que todas as possibilidades foram contempladas também é um salto qualitativo bastante grande nesses sujeitos. Ao combinar os fatores, os sujeitos deste subnível realizam as operações de conjunção, implicação, exclusão, dentre outras, o que possibilita um futuro progresso generalizador.

Para chegar à solução, os sujeitos não se contentam em encontrar algumas possibilidades, a perceber que cada uma delas faz parte de um todo maior. E mostra um pensamento proporcional relacionado à quantidade de estradas e caminhos possíveis. Quantas estradas precisas para ter nove caminhos? Três de um lado e três de outro. Posso fixar um familiar em uma cadeira e variar os outros. Quanto mais vértices mais triângulos. Tu achas que existe uma maneira de calcular sem precisar contar? Acho que sim, mas não sei qual é. Quantas tu achaste? Dez possibilidades, mas agora fiquei na dúvida se tem mais alguma.

O afirma que: São três lugares e um lugar pode estar sempre com a mesma pessoa. Há uma tentativa de criação de regra, mas ainda muito frágil por não compreender os fatores envolvidos. Em $\mathrm{P}$ verifica-se que, em alguns momentos, o êxito está relacionado à memorização de fórmulas combinatórias, mas o raciocínio combinatório, até então construído, não acompanha os cálculos. Acho que deveriam ser cinco, pois não pode repetir as letras [vértices].

O sujeito I demonstra sentir necessidade de não contradição ou de superar a contradição. E, por solicitação da experimentadora, percebe semelhanças entre suas construções. Acho que é questão de multiplicar. Agora eu tenho que multiplicar de novo. Acho que é a mesma regra (depois de explicações análogas, dá-se conta de que é a mesma lei). O que preci- 
Análise Combinatória

so fazer para ter mais caminhos? Colocar mais estradas. É proporcional. De quantas maneiras diferentes os quatro bonecos podem sentar-se nas quatro cadeiras? Cada boneco pode sentar nas quatro cadeiras, mas cada vez que um trocar de cadeira o outro tem que trocar também, então as opções são trocar 2, 3 ou 4. Faz várias tentativas com as cadeiras. Passam a fazer trocas duas a duas, encontrando quatro possibilidades para cada duas cadeiras. Acho que vou ter que fazer diferente: fixando uma das cadeiras, quantas chances as outras três tem de trocar? Posso escrever? A necessidade do registro já demonstra a necessidade de organizar as possibilidades, de maneira a contemplar todas ou para não repeti-las.

I faz diversas tentativas utilizando-se do experimento. Ainda sem utilizar o papel, testa sua teoria, mas troca os três elementos aleatoriamente de lugar. Começa a se perder nas tentativas e procura reproduzi-las no papel. Vou usar só três bonecos, depois é só multiplicar por quatro. Por que isolar um boneco? Por que daí vai ter x mudanças com os três outros e é só multiplicar por quatro, que são os lugares que o boneco isolado pode assumir. Faz as mudanças no material concreto e verifica no papel. Quantas possibilidades? Seis. E se houvesse mais um boneco? Daí, para cada troca ele poderia estar em um lugar diferente, totalizando seis vezes quatro. E dá para generalizar esse pensamento para um monte de bonecos e cadeiras? Pensa muito, mas não consegue chegar a uma conclusão precisa. Na atividade dos triângulos pensa por segmentos; tem um raciocínio sistemático, mas ainda não encontra todas as possibilidades. Fica claro que I já estudou combinatória na escola, mas reconstruiu, durante o experimento, seu próprio pensamento para pensar sobre os problemas.

O método de obtenção dos resultados possíveis progride na direção da construção de uma combinatória sistemática n a n, comprovada pelo medo de esquecer certas combinações, explicitando a necessidade de listá-las graficamente. "É apenas depois de ter feito isso, que eles [sujeitos] começam a testá-las, tentando progressivamente dissociar os fatores envolvidos e estudar os efeitos um a um - permanecendo constantes todos os outros fatores" (Piaget, 1975, p. 3).

Ao pensar hipoteticamente, o sujeito não tem mais necessidade de comprovação prática de suas hipóteses, elas passam a existir no plano das possibilidades. Nesses sujeitos, é possível perceber que possuem um método sistemático próprio, utilizado na resolução dos problemas; no entanto, essa sistematização só ocorre em um plano inconsciente. Acredito que, a partir do momento em que estes sujeitos forem capazes de tomar consciência do processo mental efetuado antes de encontrar a sua resposta, estarão muito perto de estabelecer uma combinatória completa.

\section{Subnível IIIB: necessidade de generalização}

Os sujeitos deste nível também sabem da existência de um fator geral, mas o que os diferencia dos sujeitos do nível IIIA é que sentem a 
necessidade dessa formulação. Necessidade “[...] que seja capaz de exprimir, além das relações constantes, a razão de tais relações” (Inhelder; Piaget, 1976, p. 9). O pensamento hipotético possibilita a certificação da generalidade da lei, sendo esta, agora, necessária. É importante para o sujeito verificar a veracidade da lei, mesmo que as condições empíricas sejam modificadas. As operações combinatórias, que tratam dos conjuntos das partes, constituem a lógica das proposições; distinguem-se elas dos agrupamentos de classes e relações próprios das operações concretas.

O raciocínio por hipóteses e a necessidade de demonstração sucedem à simples verificação de relações, [...] a partir de agora o pensamento utiliza juntamente o possível e o necessário, em vez de limitar-se a uma dedução a partir apenas da situação real (Inhelder; Piaget, 1976, p. 12).

O sujeito que apresenta um nível formal de pensamento, após algumas tentativas experimentais, interrompe sua ação material e passa a operar no plano das ideias, listando as hipóteses possíveis de maneira sistemática e generalizada. Depois das hipóteses criadas é que o sujeito as testa de modo a confirmá-las ou não. Para os sujeitos do nível III, fica claro que, mesmo com a limitação material dos experimentos, o pensamento não tem esse limite. O sujeito é capaz de operar para além do real, estendendo seu raciocínio ao plano das ideias. A conduta do experimentador é fundamental, no caso de instigar e questionar de forma adequada.

No nível IIIB ocorre o pensamento matemático mais refinado. Talvez por isso, tenha sido encontrados apenas um sujeito que preencheu essas características. Ele apresentou uma elaborada maneira de sistematizar e de representar graficamente seu raciocínio, apresentando, inclusive, um conceito para tal. O próprio sujeito elaborou uma estratégia de transformação do experimento em um problema mais simples, a fim de enquadrá-lo no seu atual esquema assimilador. No entanto, para compreender a equivalência de raciocínio entre um problema mais simples e outro mais complexo, estendendo seu pensamento a fim de aplicá-lo a um novo conteúdo, não é um pressuposto o sujeito já saber solucionar o primeiro problema? Essa estrutura, construída espontaneamente pelo sujeito, que alcançou esse estado de equilíbrio, mantém-se por toda a vida.

O sujeito J é o único exemplo desse nível que, embora não deduza as fórmulas próprias da Análise Combinatória, cria leis aplicáveis a diferentes conteúdos. J combina todos os fatores entre si, fazendo todas as ligações possíveis. Para ter certeza de que os elementos não foram apenas colocados em correspondência a partir, puramente, de observação ou experiência física, coloca-se o sujeito em uma situação em que os fatores necessariamente devem ser combinados, e são as suas justificativas que esclarecerão o nível de pensamento em que se encontra. 
Análise Combinatória

Na situação em que três estradas levam a casa amarela à rosa e outras três estradas levam a rosa à azul, utiliza a estratégia da multiplicação. Para cada uma [estrada] eu posso pegar outra de três maneiras. E a lógica continua quando a quantidade de caminhos não for igual? Sim, neste caso, quatro vezes três, dá doze caminhos. No acréscimo de uma casa teve de reconstruir seu raciocínio. Faz combinações de combinações e encontra, novamente, o PFC na solução dos problemas. E se tivéssemos, por exemplo, cinquenta, trinta e vinte estradas? Daí multiplica cinquenta por vinte e o resultado por trinta. No segundo experimento: continua a mesma lógica, cada um pode sentar em três lugares diferentes, então é nove. Tu podes mostrar as nove? Faz no papel, utilizando uma estratégia em que cada elemento troca de cadeira três vezes. Uma amiga tua disse que em algum momento os três estarão sentados na mesma cadeira. O que tu pensas disso que ela disse? É verdade, são seis, pois quando uma pessoa senta, não tenho mais essa cadeira para contar. Tu achas que são seis ou nove possibilidades? Seis. Podes mostrar as seis? Sistematicamente, começa a fazer as trocas.

É importante destacar que, embora no nível IIIB, o sujeito J não conseguiu construir as fórmulas algébricas utilizadas pela análise combinatória. Penso que a falta dessa última forma em nada reduz o pensamento combinatório enquanto estrutura, visto que ela é dada a partir de transformações unicamente algébricas. Para Inhelder e Piaget (1976), se o sujeito opera em um sistema proposicional que pode ser enunciado algebricamente, “[...] os raciocínios de nossos sujeitos correspondem diretamente às transformações que ligam essas operações entre si, e essas transformações correspondem, então, ao próprio cálculo que é intrínseco à própria álgebra". Mais adiante, os autores ainda acrescentam que "[...] podemos considerar o cálculo (matemático) das combinações como a aquisição primitiva, e a combinatória proposicional como uma aplicação secundária desse cálculo" (Inhelder; Piaget, 1976, p. 232). Continuando,

[...] esta álgebra não constitui, para a psicologia, mais que uma tradução simbólica, cuja utilidade essencial é a de um cálculo. Mas a realidade dos fatos que recobre essa tradução simbólica é a de um campo de ações coordenadas (Inhelder; Piaget, 1976, p. 248).

As tomadas de consciência são claras durante a prova, permitindo que J apresente um raciocínio combinatório completo. É como as estradas, mantém-se a primeira e mudam-se as outras duas, depois se volta para mudar a primeira. Enumera as possibilidades. E se eu colocar mais um membro na família? Daí é quatro vezes três vezes, duas vezes um. $\mathrm{E}$ com cinco pessoas e quatro cadeiras? É o mesmo, mas sempre duas pessoas ficarão disputando onde sentar, tipo dança das cadeiras. No experimento 3, faz $\mathrm{ABC}, \mathrm{ABD}, \mathrm{ABE}$ e diz: esses são os triângulos que posso formar com A. J corrige-se espontaneamente: não, com A e B, depois posso ter os AC. $O A C B$ não pode, pois já fizemos todos os com $B$. Passa a fazer 
no papel e depois verifica os 10 triângulos. Mas deve haver uma regra. Manipulando o hexágono consegue chegar à conclusão de que a quantidade de triângulos está relacionada com a quantidade de vértices, mas ainda não chega a uma fórmula para o último experimento.

Segundo Piaget, o pensamento dedutivo, característica do pensamento operatório formal, parte de uma ideia particular para sua generalização, dando-se no plano do possível. Desta forma, nesta estrutura de pensamento, o real observado está subordinado às hipóteses possíveis. É justamente a capacidade de pensar hipoteticamente que viabiliza ao sujeito a unir todas as possibilidades entre si.

Para Piaget (1975), a tomada de consciência é o resultado de um processo construtivo, que leva o sujeito a pensar sobre o seu próprio pensamento, tomando consciência da coordenação de suas ações e das relações estabelecidas até a chegada ao resultado final. É pela tomada de consciência que o sujeito constrói conceitos. Conceitos são construídos a partir de significados que são, inicialmente, individuais para cada pessoa. Ao relacionar um conceito com outro, passamos à generalização, na qual são necessárias abstrações reflexionantes. A análise combinatória é o resultado de generalização feita a partir da ação e das coordenações das ações do sujeito, o que implica o sentimento de necessidade. Essa necessidade só vem a desempenhar seu papel quando há a tomada de consciência, que permite ao sujeito compreender os mecanismos das suas ações e, assim, chegar ao conceito - que funciona sempre como totalidade operatória.

No Quadro 2 realiza-se uma sínteses dos níveis levando-se em conta a capacidade de construção combinatória dos sujeitos de cada nível.

Quadro 2 - Síntese dos Níveis, quanto à construção da combinatória

\begin{tabular}{|c|c|}
\hline Nível I & $\begin{array}{l}\text { Características: } \\
\text { - Combinações aleatórias e não sistemáticas; } \\
\text { - Foco no resultado, e não no processo; } \\
\text { - Indiferença frente a contradições; } \\
\text { - Ausência de tomada de consciência sobre as ações. } \\
\text { - Pensamento opera sobre a materialidade (as possibilidades se } \\
\text { esgotam em algum momento); } \\
\text { - Necessidade do concreto. }\end{array}$ \\
\hline Nível II & $\begin{array}{l}\text { Características: } \\
\text { - Explicação presa ao concreto, podendo estender-se a um virtual } \\
\text { vinculado ao concreto; } \\
\text { - Teste de hipóteses sem consideração à lei geral. }\end{array}$ \\
\hline Nível III & $\begin{array}{l}\text { Características: } \\
\text { - Pensamento hipotético-dedutivo, não mais preso ao real; } \\
\text { - Foco no processo e não no resultado; } \\
\text { - Teste de hipóteses em nível mental ou para simples verificação; } \\
\text { - Tomada de consciência do processo. }\end{array}$ \\
\hline
\end{tabular}

Fonte: elaboração dos autores. 


\title{
Considerações Finais
}

O objetivo principal desta pesquisa consistiu em investigar o desenvolvimento do pensamento combinatório, enquanto constituinte de um sistema operatório formal. A capacidade de pensar formalmente permite ao jovem discutir, adotando como hipótese, além do seu o ponto de vista, o ponto de vista alheio, analisando as consequências dessa implicação, e assim julgá-la. Além disso, os interesses dos jovens passam a extrapolar as experiências físicas, compreendendo e formulando teorias, para, assim, fazer parte do mundo adulto.

No momento em que o aluno se sente provocado por determinado problema ou situação, pode-se dizer que se ligou o motor da aprendizagem. São essas situações conflituosas que tendem a mobilizar o interesse do educando para aprender. Quando entra em conflito cognitivo, o sujeito se abre para um mundo de novas descobertas. O conflito cognitivo instaura um campo de significado.

\begin{abstract}
Já que o aluno deve aprender não receptivamente, mas por seu próprio esforço, comecemos no lugar onde o esforço é menor e o resultado mais compreensível do ponto de vista do aluno: ele deve se familiarizar inicialmente com o concreto, posteriormente com o abstrato [formal]; inicialmente com a variedade de experiência e posteriormente com a unificação de conceitos etc. (Polya, 1985, p. 13).
\end{abstract}

O uso do conflito e da contra-argumentação na educação pode ajudar a desenvolver no sujeito a capacidade de assumir perspectivas diferentes frente a uma mesma situação. Essa perspectiva alheia desafia sua atual estrutura, podendo conduzi-lo à reorganização de suas estruturas cognitivas, em patamares superiores e por essa, à reformulação de suas ideias.

Tendo em vista a hipótese central deste estudo, pode-se constatar que pensamento combinatório é construído, passando por diferentes níveis de equilíbrio até a sua formalização. Investigou-se o conhecimento combinatório em diferentes idades, sendo que todos os participantes da pesquisa já haviam concluído o ensino fundamental e estavam frequentando o ensino médio, regular ou EJA. Conforme já relatado por Piaget (1975), os adultos “[...] são menos criativos e já fazem parte de uma sociedade organizada que não apenas os limita e os torna mais lentos, mas que, algumas vezes, ainda, incita-os à revolta" (Piaget, 1975, p. 8-9).

Aprender combinatória, assim como os demais conteúdos matemáticos, exige muito mais que apenas um processo de ensino. O professor deve ter pleno conhecimento de que esses conceitos, "[...] embora sejam influenciados pela experiência adquirida e pelas interações sociais, resultam de um processo interno de pensamento" (Assis; Molinári; Zaia; Rabióglio; Bessa, 2011, p. 41). Esse processo é construído, passan-

878 Educação \& Realidade, Porto Alegre, v. 40, n. 3, p. 859-882, jul./set. 2015. 
do de conhecimentos menos complexos para outros de maior complexidade em todos os seres humanos, mas segundo a hipótese de Inhelder e Piaget, ele ocorre de maneira peculiar em cada pessoa.

A conceituação se dá por tomadas de consciência, a qual se configura como um processo longo e trabalhoso no que tange às reconstruções estruturais. Construir um pensamento combinatório exige não só uma estrutura formal de pensamento, mas uma estruturação mental que possibilite ampliar este mecanismo até chegar a essa compreensão. Para isso, o raciocínio deve passar por abstrações reflexionantes realizadas pelo sujeito no plano dos possíveis. Ou seja, o sujeito deve trabalhar com hipóteses, sobre eventos inexistentes no mundo dos observáveis: as possibilidades. Os possíveis englobam os concretos reais, mas não se compõem unicamente deles. Os possíveis consideram as infinitas possibilidades em nível de pensamento, ultrapassando infinitamente o real.

Diferentes organizações de pensamento foram apresentadas nas categorias de análise, classificadas em função da complexidade dessa organização. A partir desta pesquisa, sinto-me convencida de que o raciocínio combinatório é construído, passando por sucessivos níveis até chegar a sua forma mais geral e universal. Observa-se desde a combinação aleatória de variáveis, passando por um nível intermediário onde ocorrem sucessivas sistematizações até, finalmente, a construção de um pensamento mais geral, com a necessidade da elaboração de uma lei única.

Combinatória completa é precisamente o que caracteriza o pensamento formal, cuja estrutura ultrapassa os agrupamentos aditivos ou multiplicativos de classes e de relações (com suas inferências simples e concretas fundadas sobre a transitividade das inclusões de classes ou de encadeamentos de relações) e cria a estruturação de uma lógica de proposições (Inhelder; Piaget, 1976, p. 39).

Para agrupar as combinações é necessário variar apenas um fator, deixando invariantes os demais. A lei geral é construída a partir de uma longa estruturação mental, até que atinja seu nível de equilíbrio no patamar das operações formais. A subordinação do real ao possível é uma das características do pensamento formal; todas as demais características a incluem (Parra, 1983). Neste estádio, os sujeitos operam sobre hipóteses, pensam em termos proposicionais, isolam e analisam variáveis de modo a obter todas as combinações possíveis.

O resultado obtido nos experimentos mostra que uma combinatória sistemática só aparece nos sujeitos a partir do nível IIIA. A tentativa de dissociar os fatores só é generalizada no nível formal (Inhelder; Piaget, 1976). Além disso, a lógica operatória formal "é um sistema complexo, porém coerente, que é relativamente diferente da lógica da criança, e constitui a essência da lógica dos adultos cultos e ainda proporcio- 
Análise Combinatória

na a base para as formas elementares do pensamento científico" (Piaget, 1975, p. 4). Mesmo sem descobrir as fórmulas matemáticas do cálculo das combinações, nosso sujeito do nível IIIB encontrou "[...] um processo operatório que, praticamente, equivale à aplicação da fórmula [...]” (Inhelder; Piaget, 1976, p. 233).

Os sujeitos do nível II chegam por associação e correspondências sucessivas a isolar alguns dos fatores, mas ainda não são capazes de descobrir todos os fatores a menos que presentes no real observado. Além disso, ainda não são capazes de refletir sobre a ação feita e delas tomar consciência. Essas incapacidades se devem ao fato de ainda não terem construído, estruturalmente, um método sistemático de obtenção de todas as possibilidades. O que se pode observar é que em cada nível, o sujeito estrutura seu pensamento "[...] da maneira mais completa que lhe é acessível” (Inhelder; Piaget, 1976, p. 212).

Sujeitos do Nível I não sistematizam seu pensamento. Derrapam em contradições e permanecem indiferentes a elas. Constroem combinações aleatórias, tornando impossível a construção dos possíveis, mesmo que em concretude. Pequenas sistematizações sobre o real apareceram como estrutura de pensamento dos sujeitos do Nível II. A combinação dos elementos foi construída, mas não estendida a uma lei geral. No momento em que os sujeitos passam a utilizar-se dessa nova organização sistemática, em busca de uma formalização que leve a solucionar qualquer problema semelhante, os consideramos pertencentes ao Nível III.

Uma das observações mais importantes está relacionada à continuidade demonstrada na passagem das sucessivas etapas. Percebe-se, claramente, que a transição de um nível de simples observação dos fatos a outro que opera em nível hipotético é dada de forma contínua e gradual. Em um primeiro momento, as tentativas do sujeito são de eliminar as contradições que são expostos, para, em seguida, passar a coordenar as ações entre si. A partir daí o sujeito passa a constituir uma lógica formal de pensamento em que se torna capaz de dissociar a realidade bruta, coordenando suas ações nas diversas combinações possíveis e agrupando-as em um sistema único (Inhelder; Piaget, 1976).

A construção da combinatória passa por patamares de equilíbrio que independem da idade ou série do aluno. O ensino escolar não garante a construção da combinatória, sobretudo se a aprendizagem, dele decorrente, consistiu em uma experiência de memorização mecânica, sem maior significado cognitivo. Os sujeitos mais jovens demonstraram maior quantidade e qualidade nas tomadas de consciência, enquanto os mais velhos (alunos da EJA) tentavam relacionar as situações com situações concretas e de sua vida real, mas isso não redundava em melhor qualidade argumentativa.

O desenvolvimento cognitivo de cada sujeito é único. A partir de suas ações, o sujeito tende a coordená-las de modo a estruturar sua pró-

880 Educação \& Realidade, Porto Alegre, v. 40, n. 3, p. 859-882, jul./set. 2015. 
pria realidade. Pensando dessa maneira, fica claro que o conhecimento jamais se dará por mera cópia mental da realidade. Somente agindo sobre o objeto (modificando-o e transformando-o) é que se torna possível compreendê-lo. As explicações que o sujeito dá sobre o que pensa baseiam-se na forma como está organizado o seu pensamento.

Os níveis e subníveis identificados e analisados demonstram desde uma ausência total de sistematização, até a construção da combinatória formal. Aparecem, nitidamente, entre esses sujeitos, pensamentos que privilegiam a ausência de combinações, passando por sujeitos que relacionam variáveis, efetuando dissociações e controles progressivos, até sujeitos que, por necessidade, sistematizam e unem as soluções em um sistema único e global.

Ressalta-se quão pouco numerosas foram as soluções correspondentes ao nível mais avançado de pensamento combinatório encontrados neste estudo, apesar das idades e da escolarização dos sujeitos da pesquisa. Além disso, durante a aplicação dos experimentos podemos perceber que, ao modificar as tarefas a fim de aplicar a (aqui não se trata de uma nova forma qualquer, mas da nova forma criada) nova forma a outro conteúdo, os sujeitos mostram diferenças em sua organização mental, revelada em sua capacidade explicativa. Os experimentos apresentavam diferentes graus de dificuldade quanto ao aumento sistemático do número de fatores envolvidos e quanto à complexidade do problema proposto.

Observando as explicações dadas pelos sujeitos, observamos uma progressiva abertura do pensamento na descoberta de novas possibilidades, partindo de uma relação um para um para uma relação um para muitos entre os fatores envolvidos. No entanto, novos questionamentos passam a povoar meu pensamento. Será que obteríamos os mesmos resultados se o instrumento de coleta de dados fosse outro? Isto é, quando aplicado a diferentes conteúdos, o mesmo raciocínio pode variar sua forma?

No âmbito da educação matemática, fica evidente a necessidade de que professores passem a envolver problemas de contagem, os quais exigem um pensamento combinatório mais elementar, já no ensino fundamental. Justifico isso, não apenas por sua utilidade em diferentes áreas, mas também por serem importantes no preparo da aquisição de estruturas formais de pensamento.

Recebido em 06 de agosto de 2013 Aprovado em 12 de junho de 2014

\section{Nota}

1 E.V.A. é a sigla de Etil Vinil Acetato. É um composto químico de diversos materiais que configuram uma lâmina de borracha não-tóxica que pode ser usada em diversas atividades artesanais.

Educação \& Realidade, Porto Alegre, v. 40, n. 3, p. 859-882, jul./set. 2015. 


\section{Referências}

ASSIS, Orly Z. Mantovani de; MOLINÁRI, Adriana Cirder; ZAIA, Lia Leme; RABIÓGLIO, Marta; BESSA, Sônia. O Desafio de Ensinar e Aprender Matemática na Educação Básica. Campinas: UNICAMP, 2011.

BECKER, Fernando. Epistemologia Genética e Conhecimento Matemático. In: BECKER, Fernando; FRANCO, Sérgio Roberto K. (Org.). Revisitando Piaget. 3. ed. Porto Alegre: Mediação, 1998. P. 21-48.

DELVAL, Juan. Introdução à Prática do Método Clínico: descobrindo o pensamento das crianças. Porto Alegre: Artmed, 2002.

DOLLE, Jean-Marie; BELLANO, Denis. Essas Crianças que não Aprendem: diagnósticos e terapias cognitivas. Petrópolis, RJ: Vozes, 2002.

INHELDER, Bärbel; PIAGET, Jean. Da Lógica da Criança à Lógica do Adolescente. São Paulo: Pioneira, 1976.

PARRA, Nélio. O Adolescente Segundo Piaget. São Paulo: Pioneira, 1983.

PIAGET, Jean. A Tomada de Consciência. São Paulo: EDUSP, 1975.

PIAGET, Jean et al. Abstração Reflexionante: relações lógico-aritméticas e ordem das relações espaciais. Porto Alegre: Artes Médicas, 1995.

POLYA, George. O Ensino por meio de Problemas. Revista do Professor de Matemática, São Paulo, SBM, n. 7, p. 11-16, 1985.

Mariana Lima Duro é licenciada em Matemática, especialista em Psicopedagogia Clínica e Institucional, mestra em Educação e doutoranda na mesma área. É professora de Matemática do Instituto Federal do Rio Grande do Sul - IFRS. Tem experiência na área de Educação, com ênfase em Ensino e Aprendizagem de Matemática e Epistemologia Genética.

E-mail: profmarianaduro@yahoo.com.br

Fernando Becker é doutor em Psicologia Escolar e do Desenvolvimento Humano pela USP; é Professor Titular da UFRGS. Autor de: Educação e construção do conhecimento (2a ed., Penso, 2012), Epistemologia do Professor: o cotidiano da escola (16 a ed., Vozes, 2013), Epistemologia do professor de matemática (2012, Vozes), entre outros. Publicou 23 capítulos em livros coletivos e numerosos artigos em periódicos especializados.

E-mail: f.becker@terra.com.br 